\title{
Hypothesizing if responses to climate change affect herbicide exposure risk for amphibians
}

\author{
Stefan Lötters ${ }^{1}$, Katharina J Filz ${ }^{1,2}$, Norman Wagner ${ }^{1 *}$, Benedikt R Schmidtt ${ }^{3,4}$, Christoph Emmerling ${ }^{5}$ \\ and Michael Veith ${ }^{1}$
}

\begin{abstract}
Pesticide use is well known to be detrimental for maintaining biodiversity in the agricultural landscape. Amphibians are especially affected by these agrochemicals. In particular, these animals' high sensitivity was demonstrated for glyphosate-based herbicides which are dominating the world market today. Pesticide impacts are influenced by several co-stressors, and we for the first time link the exposure risk of amphibians to these commonly used pesticides to observed recent effects from ongoing climate change. In a simple verbal model, based on present-day data from Germany, we show that amphibian populations which have undergone phenological shift towards earlier reproduction potentially suffer less from applications of glyphosate-based herbicides compared to those which (yet) show no such reproductive shift. Although, apparently observed recent climate change effects lower the exposure risk, we advocate that amphibians are not necessarily safer now, mainly because farmers most likely will adapt their cultivation practices in the future if climate change becomes more obvious. Rather, we conclude that combining pesticide applications, climate change and phenological responses need an increased consideration in amphibian conservation. The results from our verbal model should be seen as a hypothesis that needs to be tested with specific field studies and (based on these data which are widely lacking today) more complex modelling of future exposure risk of pesticides to amphibians.
\end{abstract}

Keywords: Agricultural landscape; Amphibian conservation; Model; Pesticide exposure; Phenology; Reproduction

\section{Background}

Integrating conservation of nature with the growing demand for food and modern agricultural practice is challenging $[1,2]$. A continuous problem is posed by the threat of pesticides to biodiversity [3]. Amphibians in the agricultural landscape are strongly affected by these agrochemicals due to their permeable skin and their use of both aquatic and terrestrial habitats $[4,5]$. There is evidence that effects from pesticides have the potential to significantly contribute to global amphibian population and species declines [6], although data from wild populations are sparse $[4,7]$. Among the most dangerous pesticides to amphibians are glyphosate-based herbicides with application, formulation and species- and life stage-specific effects that are mainly caused by added surfactants and not glyphosate itself [8]. Glyphosate is the active ingredient of many broad-spectrum herbicides. Although this type of

\footnotetext{
*Correspondence: wagnern@uni-trier.de

'Department of Biogeography, Trier University, 54286 Trier, Germany Full list of author information is available at the end of the article
}

herbicide is also increasingly used in conventional farming, its use in the cultivation of genetically modified crops that are made glyphosate-resistant has led to a drastic increase on the market in recent years [9]. In the USA alone, glyphosate's sales volume has increased in the period 1996 to 2007 from 25 to 180 million pounds [10].

Effects of glyphosate-based herbicides on amphibians Many of the glyphosate-based herbicide formulations available have been shown to stress amphibians [8]. Acute toxic, chronic and delayed effects at environmentally relevant and sublethal concentrations have been shown [8]. All amphibian life stages can suffer from glyphosate-based herbicides, with direct overspraying of migrating or resting terrestrial life stages (i.e. adults and juveniles) being a major threat $[5,8]$. Rapid mortal effects on aquatic larval stages have been demonstrated, mainly within the first $24 \mathrm{~h}$ after contamination [4]. Therefore, the relatively fast adsorption behaviour of glyphosate and its surfactants on soil and sediment, as well as the observed fast microbial 
degradation, cannot prevent acute toxic effects $[4,8]$. We suggest that direct contact of individuals with formulations (e.g. overspraying of adults and juveniles; first peak concentrations in breeding sites, for instance, after the first heavy rainfalls) is most relevant.

A key factor in the exposure risk is the time point when glyphosate-based herbicides are applied [8]. Taking the temperate climate zone as an example, applications of glyphosate-based herbicides can coincide with amphibian activity on fields or in ponds near fields at different time points of the year [5]. This depends on the crops being cultivated, their annual rotation and the agricultural techniques used. As a result, applications can be early in the year with pre-sowing (i.e. no-tillage farming), with pre-harvest crop desiccation (also known as siccation or controlled ripening) in summer shortly before harvesting and later in the year on stubble fields to prepare them for the sowing of winter crops [11].

The consequence is that amphibians can be exposed to glyphosate-based herbicides throughout much of their annual activity cycle. This can be manifested as follows: Adult breeding migration to ponds across fields in spring can coincide with overspraying, thus affecting the breeding population. Similarly, later in spring or summer, adults can be affected by applications when they cross field during the return from the pond to the summer habitats. Likewise, freshly metamorphosed juveniles often emerge in masses after summer rains and can be oversprayed during emigration [5]. Moreover, eggs and larval stages can be exposed to glyphosate-based herbicides due to surface water runoff and drift during larval development from early spring to summer $[8,12]$.

\section{Amphibians under climate change}

Climate change has been witnessed for several decades now [13]. Expected geographic range shifts and observed phenological changes are only two among several reasons why climate change is suggested to represent a severe threat to amphibians [14,15]. Conversely, climate change may reduce the effects of pesticides on amphibians through changes in susceptibility or exposure [16]. In the light of these findings, the increasing importance of glyphosate-based herbicides in agriculture needs specific attention. For the first time, we here link present-day glyphosate application practice to observed phenological changes in the timing of breeding activities of amphibians in response to changing climatic conditions [17-20]. Amphibians are poikilothermic animals which are highly sensitive to changing climatic conditions [15]. Besides others, phenological shifts in the annual activity pattern have been observed over the last decades in many amphibian species in temperate climate zone. Species' annual reproduction phase - from egg deposition until completion of metamorphosis - takes place from early spring to late summer. In response to warmer winter and spring temperatures, recorded for some decades now, several frogs, toads, salamanders and newts have started to reproduce earlier. Some species are now breeding up to about 1 month earlier than they did some decades ago (i.e. the observed shift is far outside the range of observed breeding dates observed during earlier decades). Phenological shifts have been reported in various species in England, Finland, France, Germany, Poland and the USA [17-23]. As a consequence of an earlier breeding season, the entire reproduction phase (breeding and larval development) can end earlier in the year [24]. We refer to these shifts as 'preterm'. Preterm behaviour may be disadvantageous to populations. For example, Reading [24] reported deteriorated body conditions in metamorphic toads (Bufo bufo) as a consequence of early breeding. Thus, preterm reproductive behaviour may lead to reduced individual fitness and reduced population growth $[18,25]$.

Phenological response to climate change can vary within a species among populations [22]. For instance, there are common frog and common toad populations in which the reproductive period starts earlier in the year but larval development then slows down so that metamorphosis is unaffected by varying the timing of breeding [25]. Moreover, there are populations of these and other species in Europe and North America which, albeit warmer winter and spring temperatures, do not show phenological shifts in breeding activity $[17,18,26-29]$. We refer to such populations as phenologically 'stable'.

Variation among populations in observed phenological shifts in response to climate change naturally lead to the question: Are amphibians differently affected by glyphosate-based herbicides when preterm compared to stable? We here present a simple verbal model to address this question. We combine present-day data from Germany as an example. That is on breeding phenology of anuran amphibians and on the timing of glyphosate applications on maize and different winter crops, as recorded between 2006 and 2008 in Germany [5]. Data on stable breeding phenology and the annual cycle are taken from Laufer et al. [30]. Besides climate change effects, the beginning and the end of reproduction periods can also depend on regional and genetical factors [22], but we here only refer to observed effects of climate change on amphibian populations. We derive maximum observed preterm scenarios by sliding activity periods for each developmental stage for 1 month (Figure 1), based on the observations made by the authors mentioned in the previous chapter. In this way, we infer overlap in preterm and stable reproductive behaviour for four species, which all occur in the agricultural landscape. Common frog (Rana temporaria) and common toad (Bufo bufo) are 'early breeders', while green toad (Pseudepidalea viridis) and common spadefoot toad (Pelobates fuscus) are 'late 


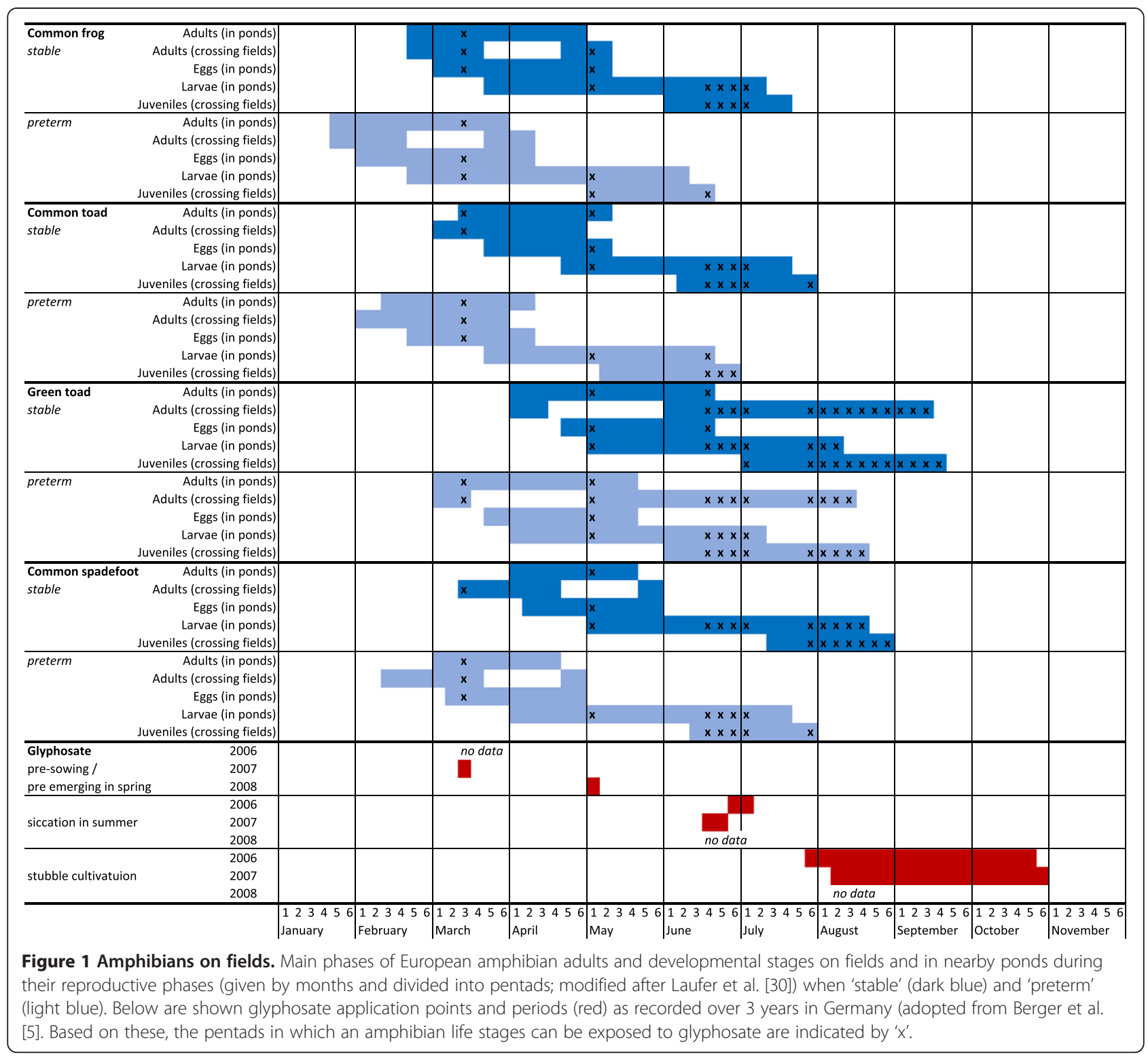

breeders'. Although, juveniles and adults of all four anurans occasionally occur on fields outside the breeding season, we consider them in our model to only cross fields during their reproductive phase.

\section{Results}

Glyphosate-based herbicides are currently applied at various time points or periods over the year [5]. As shown in Figure 1, these can coincide with the presence of all developmental stages of the four amphibian species observed on fields, no matter if being preterm or stable. However, in all species, the risk of exposure is clearly reduced in preterm populations. This becomes clear when comparing the total number of pentads per species representing the time phase of reproductive behaviour (i.e. all developmental stages pooled) with the total number of pentads in which glyphosate-based herbicides can be applied (Figure 1). In our verbal model, possible exposure decreases for about $50 \%$ in the early breeders when preterm (common frog 14 to 6 pentads, common toad 14 to 8 pentads) and also in the late breeders the decrease is moderate (green toad 38 to 27 pentads, common spadefoot 20 to 13 pentads). Early in the year, regarding possible exposure risk during pre-sowing/pre-emerging in spring, the improvement of preterm reproduction is only slight in all four species and affects adults as well as eggs. More evident, potential glyphosate applications in summer with siccation and stubble cultivation do no longer or less coincide with late larval and juvenile stages of species when preterm. 


\section{Discussion}

Our quantitative comparisons of present-day applications of glyphosate-based herbicides and current amphibian responses to climate change illustrate that preterm reproductive behaviour is advantageous both in early and late breeding amphibians. Qualitatively, this is supported by the observation that in our verbal model due to reduced exposure survival probabilities of tadpoles and metamorphosing individuals should be higher in populations displaying preterm behaviour (Figure 1). The rationale here is that post-metamorphic juveniles are highly susceptible to glyphosate-based herbicides [4] and the fact that the growth rate of amphibian populations is highly sensitive to juvenile survival [31]. Remarkably, Berger et al. [5], based on field monitoring data in Germany, noted that there was a high coincidence of these amphibian stages with glyphosate applications in stubble treatments. This is extremely reduced in preterm amphibians in our model (Figure 1).

Recent preterm behaviour is likely to reduce the exposure risk of amphibians to glyphosate-based herbicides. Thus, it appears as if preterm populations in the agricultural landscape today are safer than those showing stable reproductive behaviour. However, this conclusion should be made with caution because the link between climate change, preterm behaviour and exposure risk to pesticides raises further questions, which with our current knowledge we cannot answer. What is a lowered amphibian-glyphosate problem worth when otherwise preterm behaviour leads to a reduced size at metamorphosis, adult survival or deteriorated adult body condition $[18,24]$ ? In stable amphibians, what are the benefits of warmer temperatures, accelerating embryonic and larval development and hence reducing exposure to contaminants [16]? Last but not least, does the advantage of preterm behaviour prevail under future climate change as agricultural practice, including herbicide applications, will perhaps be subject to changes into the same direction as amphibian phenologies? The latter is most likely, i.e. that farmers will adapt their cultivation practices in the future if climate changes become more obvious.

\section{Conclusions}

Although we show that recent climate change effects might lower the exposure risk of amphibians to these pesticides, this does not necessarily imply that amphibians are safer now. Instead, by identifying newly arising questions, we advocate that combining glyphosate applications, climate change and phenological responses need more attention in amphibian conservation in the agricultural landscape.

In our simple verbal model relating amphibian phenology, exposure risk to glyphosate-based herbicides and climate change, we illustrate that observed recent phenological responses to climate change effects may lower the amphibian-glyphosate problem. However, we also clearly state that it needs to be further examined if this eventually means that preterm amphibians in the agricultural landscape are 'safer'. We hint at unanswered research questions. Therefore, we rather uncover that the combination of applications of pesticides, climate change and amphibian responses shapes a research field in need of more attention. We understand our results as a hypothesis that needs to be tested with specific monitoring and field studies and (based on these data which are widely lacking today) more complex modelling of future exposure risk of pesticides to amphibians.

\section{Competing interests}

The authors declare that they have no competing interests.

\section{Authors' contributions}

SL, KJF, NW and BRS conceived the concept of the paper and wrote the manuscript with input from CE and MV. All authors read and approved the final manuscript.

\section{Acknowledgements}

We are grateful to Carsten A. Brühl, Rick A. Relyea and Jason Rohr for their valuable comments and advice on the topic. Financial support of this paper was via the 'Graduiertenkolleg 1319 - Verbesserung von Normsetzung und Normanwendung im integrierten Umweltschutz durch rechts- und naturwissenschaftliche Kooperation' of the German Research Foundation DFG.

\section{Author details}

${ }^{1}$ Department of Biogeography, Trier University, 54286 Trier, Germany. ${ }^{2}$ Museum für Naturkunde Dortmund, Münsterstraße 271, 44145 Dortmund, Germany. ${ }^{3}$ KARCH, Passage Maximilien-de-Meuron 6, 2000 Neuchâtel, Switzerland. ${ }^{4}$ Institute of Evolutionary Biology and Environmental Studies, University of Zurich, Winterthurerstrasse 190, 8057 Zurich, Switzerland. ${ }^{5}$ Department of Soil Science, Trier University, 54286 Trier, Germany.

Received: 27 July 2014 Accepted: 16 November 2014

Published online: 02 December 2014

\section{References}

1. Kumaraswamy S, Kunte K: Integrating biodiversity and conservation with modern agricultural landscapes. Biodivers Conserv 2013, 22:2735-2750.

2. Pe'er G, Dicks LV, Visconti P, Arlettaz R, Báldi A, Benton TG, Collins S, Dieterich M, Gregory RD, Hartig F, Henle K, Hobson PR, Kleijn D, Neumann RK, Robijns T, Schmidt J, Shwartz A, Sutherland WJ, Turbé A, Wulf F, Scott AV: EU agricultural reform fails on biodiversity. Science 2014, 344:1090-1092.

3. Geiger F, Bengtsson J, Berendse F, Weisser WW, Emmerson M, Morales MB, Ceryngier P, Liira J, Tscharntke T, Winqvist C, Eggers S, Bommarco R, Pärt T, Bretagnolle V, Plantegenest M, Clement LW, Dennis C, Palmer C, Oñate JJ, Guerrero I, Hawro V, Aavik T, Thies C, Flohre A, Hänke S, Fischer C, Goedhart PW, Inchausti P: Persistent negative effects of pesticides on biodiversity and biological control potential on European farmland. Basic Appl Ecol 2010, 11:97-105.

4. Relyea RA: The lethal impact of roundup on aquatic and terrestrial amphibians. Ecol App/ 2005, 15:1118-1124.

5. Berger G, Graef F, Pfeffer H: Glyphosate applications on arable fields considerably coincide with migrating amphibians. Sci Rep 2013, 3:2622.

6. Collins JP, Storfer A: Global amphibian declines: sorting the hypotheses. Divers Distrib 2003, 9:89-98.

7. Mann RM, Hyne RV, Choung CB, Wilson SP: Amphibians and agricultural chemicals: review of the risks in a complex environment. Environ Pollut 2009, 157:2903-2927. 
8. Wagner N, Reichenbecher W, Teichmann H, Tappeser B, Lötters S: Questions concerning the potential impact of glyphosate-based herbicides on amphibians. Environ Toxicol Chem 2013, 32:1688-1700

9. Dill GM: Glyphosate-resistant crops: history, status and future. Pest Manag Sci 2005, 61:219-224.

10. Grube A, Donaldson D, Kiely T, Wu L: Pesticides Industry Sales and Usage 2006 and 2007 Market Estimates. Washington, DC: United States Environmental Protection Agency (US EPA); 2011.

11. Steinmann HH, Dickeduisberg $M$, Theuvsen $L$ : Uses and benefits of glyphosate in German arable farming. Crop Protect 2012, 42:164-169.

12. Brown $C D$, van Beinum W: Pesticide transport via sub-surface drains in Europe. Environ Pollut 2009, 157:3314-3324.

13. IPCC (Intergovernmental Panel on Climate Change): Climate Change: Impacts, Adaptation and Vulnerability, Contribution of WG II to the Fourth Assessment Report of the Intergovernmental Panel on Climate Change. Cambridge, UK: Cambridge University Press; 2007.

14. Araújo MB, Thuiller W, Pearson RG: Climate warming and the decline of amphibians and reptiles in Europe. J Biogeogr 2006, 33:1712-1728.

15. Foden WB, Butchart SHM, Stuart SN, Vié J-C, Akçakaya RH, Angulo A, DeVantier LM, Gutsche A, Turak E, Cao L, Donner SD, Katariya V, Bernard R, Holland RA, Hughes AF, O'Hanlon SE, Garnett ST, Şekercioğlu ÇH, Mace GM: Identifying the world's most climate change vulnerable species: a systematic trait-based assessment of all birds, amphibians and corals. PLoS One 2013, 8:e65427.

16. Rohr JR, Sesterhenn TM, Stieha C: Will climate change reduce the effects of a pesticide on amphibians?: partitioning effects on exposure and susceptibility to contaminants. Glob Change Biol 2011, 17:657-666.

17. Beebee TJC: Amphibian breeding and climate. Nature 1995, 374:219-220.

18. Blaustein AR, Belden LK, Olson DH, Green DM, Root TL, Kiesecker JM: Amphibian breeding and climate change. Conserv Bio/ 2001, 15:1804-1809.

19. Tryjanowski P, Rybacki M, Sparks T: Changes in the first spawning dates of common frogs and common toads in western Poland in 1978-2002. Ann Zool Fenn 2003, 40:459-464.

20. Neveu A: Incidence of climate on common frog breeding: long-term and short-term changes. Acta Oecol 2009, 35:671-678.

21. Terhivuo J: Phenology of spawning for the common frog (Rana temporaria $\mathrm{L}$.) in Finland from 1846 to 1986. Ann Zool Fenn 1988, 25:165-175.

22. Phillimore $A B$, Hadfield JD, Jones $O R$, Smithers RJ: Differences in spawning date between populations of common frog reveal local adaptation. Proc Natl Acad Sci U S A 2010, 107:8292-8297.

23. Münch D: Populationsentwicklung und klimatisch veränderte Frühjahrsaktivität von Erdkröte, Teichmolch, Bergmolch und Kammolch an der Höfkerstraße am NSG Hallerey in Dortmund 1981-1997. Dortmund Beitr Landesk 1998, 32:89-106.

24. Reading $\mathrm{CJ}$ : The impact of environmental temperature on larval development and metamorph body condition in the common toad, Bufo bufo. Amphibia Reptilia 2010, 31:483-488.

25. Reading CJ, Clarke RT: Impacts of climate and density on the duration of the tadpole stage of the common toad Bufo bufo. Oecologia 1999, 121:310-315.

26. Reading $\mathrm{CJ}$ : The effect of winter temperatures on the timing of breeding activity in the common toad, Bufo bufo. Oecologia 1998, 117:469-475.

27. Reading CJ: The effects of variation in climatic temperature (1980-2001) on breeding activity and tadpole stage duration in the common toad, Bufo bufo. Sci Total Environ 2003, 310:1-3.

28. Gibbs JP, Breisch AR: Climate warming and calling phenology of frogs near Ithaca, New York, 1900-1999. Conserv Biol 2001, 15:1175-1178.

29. Parmesan C: Influences of species, latitudes, methodologies on estimates of phenological responses to global warming. Glob Change Biol 2007, 13:1860-1872

30. Laufer H, Fritz K, Sowig P: Die Amphibien und Reptilien Baden-Württembergs. Stuttgart: Ulmer; 2007.

31. Hels T, Nachman G: Simulating viability of a spadefoot toad Pelobates fuscus metapopulation in a landscape fragmented by a road. Ecography 2002, 25:730-744

doi:10.1186/s12302-014-0031-4

Cite this article as: Lötters et al: Hypothesizing if responses to climate change affect herbicide exposure risk for amphibians. Environmental Sciences Europe 2014 26:31.

\section{Submit your manuscript to a SpringerOpen ${ }^{\circ}$ journal and benefit from:}

- Convenient online submission

- Rigorous peer review

- Immediate publication on acceptance

- Open access: articles freely available online

- High visibility within the field

- Retaining the copyright to your article

Submit your next manuscript at $>$ springeropen.com 